College of France in 1837-8, alluding to the veins, says, "Too many examples are unfortunately on record of the occurrence of fatal results through the accidental entry of air in this manner." He continues: "I have published an essay on the subject, and I presume you remember the experiments I made before you, in the course of which I explained the best manner of preventing or remedying this formidable oceurrence. Whenever a surgeon practises an operation close to the thorax, he should take care to be provided with an instrument fitted for the withdrawing of any air that might accidentally enter the veins, and through them the right cavities of the heart. The chief symptoms of such entry are, a peculiar sibilus, tumultuous pulsation in the chest, and spontaneous syncope.

"It is not the deleterious action of the air on the living tissues that causes death, but the stoppage of the circulation, which takes place in consequence of the ventricle having nothing to contract on but a spurious mass, incapable of traversing the vessels. The sole means of saving the life of the patient consists in aspiring the froth accumulated in the right side of the heart before too large a quantity has reached the lungs and left side of the heart. I say, too large a quantity, advisedly; for it is not true that a single bubble of air mixing with the blood will induce death. I am aware that this assertion makes somewhat light of the organic sensibility of the capillaries, concerning which such marvels are related; but the fact may be easily verified by any of you. Open the jugular of a dog, and inject air into it, taking the precaution to perform the operation extremely slowly; the animal will continue to live after receiving into its veins not a single bubble, but an entire syringeful of that fluid. Next vary the experiment, by pushing the piston rapidly; you will find that death follows instantaneously; the difference in effect depends on the manner in which you cause the entry of the air. In one case the air reaches the blood gradually by successive bubbles; its presence in the smaller vessels constitutes no obstacle to the continuance of the pulmonary and general circulation. When, on the contrary, you suddenly force in a considerable volume of air, that fluid, dilated by the heat of the organs, distends the walls of the ventricles to such a degree that they cannot contract. The movement which subsequently takes place in the heart depends on contractions of the left ventricle, the right cavities have scarcely any share in it. Hence the importance of causing an assistant to compress, or of tying the cardiac orifice of, any good sized vein that may chance to be opened in the neighbourhood of the chest. And in the application of a ligature there are certain precautions to be taken: you must be careful not to raise the vessel, by introducing one of the branches of your forceps into the interior, and applying the other to its outside; in this way, acting on one side only of the cylinder, you run the risk of permitting the air to enter when you draw the vessel from the wound. The best plan is, obviously, to seize the vein by its external surface, and then tighten the ligature." "So dangerous did M. Bouchon consider operations about the chest, that he recommended them to be performed under water. Bichât long ago pointed out the effects of the admission of air into veins." Further, independently of accidental circum. stances which prevent veins from closing after division of their parietes, M. Berard, the present eminent professor of physiology at the School of Medicine of Paris, has pointed out a natural anatomical cause, which merits the special attention of surgeons. This consists in the fact, that the principal branches of the vena cava superior in the vicinity of the heart have connexions with the aponeurotic lamine of the cervical regions, so formed, that the parietes of these vessels are kept in a continual state of tension; so that the veins form so many canals, that are more inclined to remain open than to close. The vast importance of a knowledge of this anatomical pecufiarity in operations upon the neck and parts about the chest, will be apparent, and go to show that bleeding in the jugular vein is not so trifling an operation as is supposed by many.

In the American Joumal for August, 1822, there are observations upon the entry of air into the veins during operations, by John C. Warren, M.D., Professor of Anatomy in the Harvard University, U.S. America.

The following eminent men have also written on the subject, giving cases:-MM. Amussat, Mercier, Poisseville, Denot, Bouilland, Velpeau, Basse, Mayor, Burley, Godemer, Blandin, Marshal, (de Calvi,) Ribere, Malgaigne, J. Guérin, \&c.*

With reference to the question put to Dr. M'Cormack at the inquest held on the subject of the unfortunate occurrence, * A case of death from the entrance of air into the veins, occurring in one of the French hospitals, will also be found detailed in THE LANCET for $1842-3$, vol, i. p. 461 , and remarks upon the same at p. 475 .
"Is it the treatment generally adopted by surgeons in this country?"- his reply was, "To the best of my knowledge no case has occurred till the present, (referring, I presume, to his special studies and experiments made in 1837,) to put in practice the results I alluded to." But in the Medico-Chirurgical Transactions for December, 1843, there is recorded a case of alarming syncope from the admission of air into a vein during an amputation at the shoulder-joint, by Bransby $B$. Cooper, Esq., F.R.S. It occurred at Guy's Hospital, on the 17th of May, 1843.

The importance of the subject I trust, Mr. Editor, will be a sufficient apology for trespassing thus largely on your columns. The matter given will also show, that however remarkable the occurrence of air getting into the veins during operations, and causing death, may be, such an occurrence is by no means rare.

London, April, 1848.

REPORT OF A

\section{CASE OF SPONTANEOUS RUPTURE OF THE} UTERUS BEFORE LABOUR.

\section{By THOMAS F. BROWNBILL, Ess.,} SURGEON TO THE SALFORD WORKHOUSE.

M. A. G- aged twenty-eight years, was of rather short stature, well proportioned, and had a healthy appearance. She had been married about eight years. In ten months subsequent to marriage, after an ordinary labour of about nine hours' duration, she gave birth to a full-grown female child, which lived about four months. Soon after labour, which I understand was quite natural, she was seized with convulsions, followed by delirium \&c., which, continuing for a week or ten days, subsequently resulted in an attack of puerperal mania, for which she was afterwards admitted into the Manchester Workhouse. Here she remained about two months, and, as no improvement had taken place, was then sent to Lancaster Asylum, whence, having been confined seven or eight months, she was discharged cured; and from that until a recent period had enjoyed uninterrupted good health. Having been separated from her husband during most of the time since her last confinement, she again became pregnant, and was admitted into the Salford Workhouse on the 4 th of November last, in order to lie in. She stated that, in the beginning of the seventh month of gestation, whilst hanging out some clothes, she received a fall, which shook her violently, but did not cause her, either then or afterwards, any particular pain. On the 20 th of November, at six A.M. after having passed a restless night, with occasional slight uterine pains, she began to vomit. This was followed by several pretty strong pains, during one of which she experienced (to use her own expression) a severe crack in the back, with a feeling of something suddenly giving way in her inside, which was immediately followed by a discharge of liquor amnii from the vagina. The midwife (an intelligent and experienced person) was accordingly sent for, and was soon in attendance. She found, upon examination, the os uteri nearly closed, hard, and incapable of admitting the point of the finger. There was a slight discharge, of a dark brown colour, from the vagina; the patient had vomited the contents of the stomach; and the pains had altogether subsided. Under these circumstances, she left her, and found, on her return, at three P.M., she had had no pain during her absence. The os uteri was lower down, and more yielding, though not in the least dilated, and a slight discharge of water, tinged with blood, escaped whilst making the examination. She had not slept nor felt the motion of the child since soon after the membranes broke. A dose of castor oil was now ordered. On visiting her the following evening, at nine P.M., at the request of Mr. Roberts, the governor of the workhouse, I found the oil had been rejected by the stomach, and the vomiting had more or less continued to the present time, the matter at first being of a greenish yellow, and afterwards of a chocolate colour. Labour had not in the least progressed, the os uteri remaining as before, if anything, more contracted. She had no pains; complained of being weak and poorly; and although several opiates had at short intervals been adminis tered, she had as yet not slept; and with a feeble pulse. Her countenance now began to assume an anxious expression.

Nov. 22nd.-About eleven A.M. she began to doze for short periods, but this state soon gave way to extreme restlessness, almost incessantly requiring her position to be altered. She now complained of severe pain in the middle of her back, and her pulse was evidently sinking. Between one and two 
o'clock her breathing became laborions; her finger-nails had turned livid; continued gasping ensued; and in this state she died.

The body was inspected twenty-four hours after death, in the presence of several medical friends, and Mr. Roberts, the governor. 'The abdomen was found to contain a large quantity (about two pints) of dark-coloured, uncoagulated blood, probably diluted with a portion of the liquor amnii; and this being partially removed, the first object that presented itself, entirely excluded from the womb, and partially covered by the omentum and small intestines, was a full-grown male child, that had evidently been dead several days, the first stage of putrefaction having commenced. On partially removing the child, which lay with its left shoulder to the womb, a large rupture of this organ was observed, extending from the centre of the fundus, posteriorly, along its whole length as far as the os uteri, having only a narrow rim surrounding it, and through which the child had escaped into the cavity of the abdomen. The length of the opening was about seven inches, and the uterus, which seemed perfectly healthy, was well contracted over the firmly adherent placenta. In the above unfortunate case there are several points worthy of general notice, and which are of peculiar interest to the obstetrician. The patient was at the end of her calculation, and had a well-tormed pelvis. The child was full-grown, of average size, also well-formed, and there existed between the two no disparity which would prevent the one easily passing through the other, supposing the presentation to be natural. From the time she first began to complain, up to her death, there was not the slightest pressure downwards; the os uteri was not at all dilated, and it firmly resisted the introduction of the finger-point, which effectually prevented my ascertaining the presentation of the child; nor was there any particular point or bulging perceptible in any part surrounding the os uteri, by which I could recognise its position. The os uteri projected downward a little way into the vagina, and above it seemed to lead to an unobliterated cervix. Notwithstanding this state of things, from the total absence, since the first coinmencement, of anything like strong or bearing-down labour-pains, even at the time the waters escaped, it never occurred to me that the uterus had probably ruptured, which fact I first discovered at the postmortem examination. The cause of the rupture is involved in much obscurity. She had not over-exerted herself, nor had she received any bodily injury since the time she fell; and the shake the fall occasioned was not followed by any soreness or other inconvenience. Towards the end of gestation she was often low-spirited, and entertained a presenti. ment, to which she often gave expression, that she should not survive the birth of her child. There was no softening of structure in the uterus, nor any indication of previous inflammation. The surrounding soft parts were healthy. The usual predisposing and exciting causes were all absent. Fven supposing there were malposition of the fotus, that the wall of the uterus should be endangered from such trivial pains seems surprising. The case altogether is remarkable, and it presents an instance of the least frequent form, as I believed, of this lesion-viz., the longitudinal rupture of this organ, extending from the centre of the fundus, posteriorly, in a straight direction, to within half an inch of the posterior margin of the os uteri.

Salford, 1848

\section{ON THE INHALATION OF CHLOROFORM, \&C.}

\section{By J. ROBINSON, Ese., London.}

A correspondent, in The Laycer of last week, "wishes to be informed as to the largest quantity of chloroform inhaled at one time, and the longest period a patient has been kept fully under its influence when being operated on, and whether any ill effects followed its exhibition."

Having administered this agent in a large number of cases, for our operating surgeons, I select the following from the many, as the result of my own experience.

For the removal of the breast of a female, about thirty years of age, operated on by Mr. Wade, the patient inhaled four drachms of the chloroform, and was kept fully under its influence for a quarter of an hour, including the dressing, \&c. Its exhibition was followed by slight vomiting only. The patient has recovered.

In Mr. Thomas Wakley's operation on the foot, (which has been reported in THE LANCET, ) the patient was kept perfectly quiescent for upwards of twenty minutes, including the introduction of sixteen sutures \&c., having, during the operation and its completion, inhaled six drachms of the chloroform. No nausea or unpleasant symptoms followed the inhalation, since which the patient has been discharged from the hospital, cured.

In the case of a young lady, of a highly nervous temperament, twenty-two years of age, a patient under the care of Dr. Roots, consulted me in reference to her teeth, and from whom I deemed it necessary to remove fourteen teeth and stumps, independently of excising the edges of the alveolar process, for the purpose of hastening the process of absorp. tion, for the introduction of a temporary substitute. She inhaled four drachms and a half of the chloroform, but experienced no nausea or unpleasant effect further than a few hours debility, consequent upon taking a powerful stimulus.

In the case of a private patient of Mr. Morton, of University Hospital, a gentleman had suffered for years with an irritable stricture of the uretlira, of the most obstinate character, and so exquisitely sensitive was he to the introduction of a catheter, that it was deemed advisable to have recourse to the anæsthetic agent. I administered the chloroform to the extent of five drachms, and he was under its full influence for three quarters of an hour. The patient afterwards called upon me, and expressed himself as not having suffered the least inconvenience in his general health, but that he had been perfectly cured by the operation.

In a recent operation at the Royal Free Hospital, for the removal of the ramus of the inferior maxillary bone, by $\mathrm{Mr}$. Thomas Wakley, I administered the chloroform to a young man, apparently twenty-five years of age, of a robust and plethoric habit, who inhaled six drachms of the agent during the operation and its completion, keeping him perfectly quiescent during the entire period, and until he had been removed to his ward. In this case, violent vomiting followed the completion of the operation, through the mistaken kindness of the hospital nurse, who had, an hour previously, furnished him with his usual meal of meat and porter, in contradirection to the expressed orders of the surgeon. This patient also experienced no ill effects from the quantity inhaled, but is discharged from the hospital, cured.

Gower-street, June, 1848.

\section{Analuses}

\section{COMMUNICATIONS IN MS. RECEIVED FOR PUBLICATION IN THE LANCET.}

" L'auteur se tue à allonger ce que le lecteur se tue à abréger."

On Involuntary Nocturnal, Micturition.

A conRespondent, in reference to the debate in the Medical Society of London, on the above subject, as published in THE LANCLT, on the 27 th of May, remarks-"The existence or non-existence of a sphincter vesica seemed to claim the great share of attention from the speakers; but whether there be such a muscle or not, keeping watch over the outlet of the bladder, matters little, in my opinion, in regard to the treatment of this affection. We have an imherent power residing in the urethral canal, quite sufficient, under ordinary circumstances, to prevent the flow of urine from the bladder unless when overcome by the usual voluntary efforts at micturition, the common constrictor muscles of the neck of the bladder being excited to contraction by the stimulus of the urine on the adjacent mucous coat, sufficient to counteract the contraction of the expulsatory muscles excited by reflex action.

I should be inclined to divide the causes of juvenile involuntary nocturnal micturition into three heads, which it will be found most important to keep in mind in the management of these cases:-First, I would instance abnormal reflex spinal action, or derangement of that nervous circle; secondly, where the balance betwcen the irritability of the mucous membrane of the bladder and the stimulus of its contents is upset; and thirdly, where the sleep of the patient is so deep that he is not aroused to the consciousness of the act of micturition, so as to be able to bring the voluntary muscles into operation.

The bladder is supplied by excito-motory and common motory nerves from the spinal column, and surrounded both by voluntary and involuntary muscles; and these again are arranged so as to act either in expelling its contents, or constricting its outlet so as to prevent their exit. The contents of the bladder form the natural stimulus to the contraction of these muscles; but unless when it is too full, or these contents are of an acrid or irritating nature, the two classes of muscles are perfectly balanced, and it is only when the voluntary ex- 